\title{
Preoperative opioid strength may not affect outcomes of anterior cervical procedures: a post hoc analysis of 2 prospective, randomized trials
}

\author{
Michael P. Kelly, MD, ${ }^{1}$ Paul A. Anderson, MD, ${ }^{2}$ Rick C. Sasso, MD, ${ }^{3}$ and K. Daniel Riew, MD ${ }^{1}$ \\ ${ }^{1}$ Department of Orthopedic Surgery, Washington University School of Medicine, Saint Louis, Missouri; ${ }^{2}$ Department of \\ Orthopedics \& Rehabilitation, University of Wisconsin, Madison, Wisconsin; and ${ }^{3}$ Department of Orthopedic Surgery, Indiana \\ Spine Group, Indianapolis, Indiana
}

OBJECT The aim of this study is to evaluate the relationship between preoperative opioid strength and outcomes of anterior cervical decompressive surgery.

METHODS A retrospective cohort of 1004 patients enrolled in 1 of 2 investigational device exemption studies comparing cervical total disc arthroplasty (TDA) and anterior cervical discectomy and fusion (ACDF) for single-level cervical disease causing radiculopathy or myelopathy was selected. At a preoperative visit, opioid use data, Neck Disability Index (NDI) scores, 36-Item Short-Form Health Survey (SF-36) scores, and numeric rating scale scores for neck and arm pain were collected. Patients were divided into strong (oxycodone/morphine/meperidine), weak (codeine/propoxyphene/ hydrocodone), and opioid-naïve groups. Preoperative and postoperative (24 months) outcomes scores were compared within and between groups using the paired t-test and ANCOVA, respectively.

RESULTS Patients were categorized as follows: 226 strong, 762 weak, and 16 opioid naïve. The strong and weak groups were similar with respect to age, sex, race, marital status, education level, Worker's Compensation status, litigation status, and alcohol use. At 24-month follow-up, no differences in change in arm or neck pain scores (arm: strong -52.3, weak -50.6, naïve -54.0, $p=0.244$; neck: strong -52.7, weak -50.8, naïve -44.6, $p=0.355$ ); NDI scores (strong -36.0, weak -33.3, naïve -32.3, $p=0.181$ ); or SF-36 Physical Component Summary scores (strong: 14.1, weak 13.3, naïve 21.7, $p=0.317$ ) were present. Using a 15-point improvement in NDI to determine success, the authors found no between-groups difference in success rates (strong $80.6 \%$, weak $82.7 \%$, naïve $73.3 \%, p=0.134$ ). No difference existed between treatment arms (TDA vs ACDF) for any outcome at any time point.

CONCLUSIONS Preoperative opioid strength did not adversely affect outcomes in this analysis. Careful patient selection can yield good results in this patient population.

http://thejns.org/doi/abs/10.3171/2015.1.SPINE14985

KEY WORDS narcotic; pain; cervical fusion; cervical arthroplasty; opioid

$\mathrm{P}$ REOPERATIVE opioid use is thought to be associated with poorer patient outcomes compared with not using opioids, particularly in patients with musculoskeletal disease. ${ }^{5,6,15}$ Physicians must balance pain relief with the risks of opioid tolerance, chronic use, and difficult postoperative pain control. Patients receiving opioids prior to nonoperative management have been shown to have higher rates of noncompliance to their directed care

\footnotetext{
ABBREVIATIONS ACDF = anterior cervical discectomy and fusion; IDE = investigational device exemption; MCS = Mental Component Summary; NDI = Neck Disability Index; PCS = Physical Component Summary; SF-36 = 36-Item Short-Form Health Survey; TDA = total disc arthroplasty.

SUBMITTED September 29, 2014. ACCEPTED January 19, 2015.

INCLUDE WHEN CITING Published online July 3, 2015; DOI: 10.3171/2015.1.SPINE14985.

DISCLOSURE Medtronic provided direct research support for this project. Research reported in this publication was supported by the Washington University Institute of Clinical and Translational Sciences grant UL1 TR000448 from the National Center for Advancing Translational Sciences of the NIH. The content is solely the responsibility of the authors and does not necessarily represent the official view of the NIH. Dr. Riew reports direct stock ownership in Amedica, Benvenue, Expanding Orthopedics, Nexgen Spine, Osprey, Paradigm Spine, Spinal Kinetics, Spineology, Vertiflex, and PSD; receiving research support for the study described from AO Spine, Cerapedics, Medtronic, OREF (Orthopaedic Research and Education Foundation), and Spinal Dynamics; receiving royalties and speaker honoraria from and/or being a board member for Biomet, Medtronic, Osprey, CSRS (Cervical Spine Research Society), Korean American Spine Society, Global Spine Journal, Spine Journal, AO Spine International, New England Spine Society Group, and North American Spine Society. Dr. Anderson reports being a consultant for Aesculap and Stryker; holding a patent with Stryker and RTI; having ownership in SI Bone, Spartec, Titan Spine, and Expanding Orthopedics. Dr. Kelly reports receiving support from AO Spine, CSRS, OREF, and Barnes Jewish Foundation for non-study-related clinical or research efforts.
} 
and also undergo surgery more frequently than those without pretreatment narcotics. Additionally, opioid tolerance and opioid-induced hyperalgesia may complicate postoperative care and negatively affect outcomes related with surgery. These concerns are supported in studies of both total knee arthroplasty and cervical discectomy and fusion patients. ${ }^{6,15}$

Anterior cervical discectomy and fusion (ACDF) and cervical total disc arthroplasty (TDA) are used in the management of both radiculopathy and myelopathy with excellent success. ${ }^{4,8,9,12}$ Several studies have investigated outcome predictors of these anterior decompressive procedures. ${ }^{1,10}$ Among reported predictors of poor results were exposure to lower-strength opioids, high disability scores, and higher preoperative pain scores. That lower-strength opioids would be associated with poor results is counterintuitive, and the effect of preoperative opioid exposure on the results of anterior decompressive surgery has not been well examined. We hypothesized that exposure to strong opioids prior to an anterior cervical decompressive procedure would be associated with less improvement in outcomes scores. To investigate this hypothesis, we sought to measure the association between preoperative opioid strength and patient-centered outcomes following ACDF and TDA from 2 prospective, randomized, controlled trials.

\section{Methods}

A post hoc analysis of data from 2 prospective, multicenter, randomized U.S. Food and Drug Administration investigational device exemption (IDE) studies was performed. These studies compared the Prestige cervical arthroplasty and the Bryan cervical arthroplasty (Medtronic Sofamor Danek) (TDA) with ACDF for the management of single-level cervical disc disease. The protocols for these studies have been previously published..$^{4,8}$ Institutional review board approval was obtained at all participating centers. Informed consent for study participation was obtained from all patients. All patients presented with single-level, degenerative cervical disc disease causing radiculopathy, myelopathy, or both and a Neck Disability Index (NDI) score equal to or greater than 30. All patients had symptoms for a minimum of 6 weeks and underwent 6 weeks of nonoperative management, unless they continued to show neurological deterioration. Pertinent exclusion criteria included any prior cervical spine surgery, diabetes mellitus, inflammatory arthropathies (e.g., rheumatoid arthritis), or evidence of segmental instability on flexionextension films. Patients with a medical condition treated with long-term steroids or nonsteroidal antiinflammatory medications were also excluded. Patients with prior or active histories of alcohol or drug abuse or dependency were excluded. All patients were treated with an anterior decompressive procedure, with either ACDF or TDA. All patients were given routine postoperative care.

At enrollment, all patients responded to a questionnaire regarding their narcotic use. Opioid use was recorded on intake forms as "weak" narcotic medication (e.g., codeine, propoxyphene, hydrocodone) or "strong" narcotic medication (e.g., oxycodone, morphine, meperidine), according to morphine equivalents and standard prescribed dosages. Patients were thus categorized into the following groups: opioid naïve, weak opioid, and strong opioid. In addition to standard demographic information, 36-Item Short-Form Health Survey (SF-36) scores, NDI scores, and numeric pain rating scores for arm pain and neck pain were obtained at the baseline, 6-month, 12-month, and 24-month follow-up visits. Success was defined as a 15-point or greater improvement in the NDI. Patients were asked if they felt surgery was a success or failure, if surgery was as effective as they had hoped, and if they would have chosen surgery again for the same condition. Return to work was evaluated at each follow-up visit.

Preoperative and postoperative scores were compared within groups, using the Student t-test, and between groups, using ANCOVA, at each time point, using preoperative scores as a covariate. Logistic regression was used to compare the dichotomous outcome of success, controlling for preoperative NDI scores. SAS statistical software was used. Statistical significance was defined as $\mathrm{p}<0.05$.

\section{Results}

\section{Patient Demographics}

There were 1004 patients identified with baseline and follow-up data in the 2 IDE studies. Of these, 226 patients $(22.5 \%)$ reported use of strong opioids at the time of enrollment, and 762 patients $(75.9 \%)$ reported use of weak opioids at the time of enrollment. Only 16 patients $(1.6 \%)$ reported no narcotic use at the time of enrollment. Given the small size of the opioid-naïve group, no statistical comparisons were made between this group and the weak or strong groups, and only comparisons between the latter two groups were performed.

The mean age of enrolled patients was similar between groups, and sex and race were distributed similarly between groups (Table 1). Marital status, level of maximum education, and alcohol use were similar among groups. Tobacco use was significantly more common in the strong opioid group (38.5\%) versus the weak opioid group $(27.8 \%)$. Patients in the strong opioid group were less likely to be working prior to surgery, when compared with weak opioid users $(52.2 \%$ and $68.2 \%, \mathrm{p}=0.001)$.

\section{Baseline Severity of Disease}

Patients taking strong narcotics had higher baseline NDI scores, more neck pain, and more arm pain than the weak opioid cohort (Tables 2-4). Preoperative SF-36 Physical Component Summary (PCS) scores were lower in the strong opioid group (more disability), though the difference was small and perhaps of no clinical meaning (strong: $29.2 \pm 12.4$; weak: $32.9 \pm 14.4, \mathrm{p}<0.001$; naïve: $31.0 \pm 12.0$ ). Similarly, a small, but statistically significant, difference in preoperative SF-36 Mental Component Summary (MCS) scores was observed, with the strong opioid group showing slightly more disability (strong: $40.3 \pm$ 24.0; weak: $43.7 \pm 24.2 ; \mathrm{p}<0.001$, naïve: $46.5 \pm 28.4$ ).

\section{Outcomes}

Mean improvement in NDI score was 36.3 points in the strong and 33.5 points in the weak cohorts. This differ- 
TABLE 1. Demographic data

\begin{tabular}{|c|c|c|c|c|}
\hline Variable & Strong Opioid $n=226$ & Weak Opioid n = 762 & p Value* & Naïve $n=16$ \\
\hline Mean age in yrs (SD) & $43.4(8.0)$ & $44.1(8.3)$ & 0.217 & $47.6(6.9)$ \\
\hline \multicolumn{5}{|l|}{ Sex, n (\%) } \\
\hline M & $104(46)$ & $362(47.5)$ & 0.705 & $7(43.8)$ \\
\hline $\mathrm{F}$ & $122(54)$ & $400(52.5)$ & & $9(56.3)$ \\
\hline \multicolumn{5}{|l|}{ Race, $n(\%)$} \\
\hline Caucasian & $211(93.4)$ & $713(93.6)$ & 0.885 & $14(87.5)$ \\
\hline African American & $5(2.2)$ & $21(2.8)$ & & $1(6.3)$ \\
\hline Asian & $1(0.4)$ & $5(0.7)$ & & 0 \\
\hline Hispanic & $6(2.7)$ & $17(2.2)$ & & 0 \\
\hline Other & $3(1.3)$ & $6(0.8)$ & & $1(6.3)$ \\
\hline \multicolumn{5}{|c|}{ Worker's Compensation, $\mathrm{n}(\%)$} \\
\hline Yes & 27 (12.2) & $66(8.7)$ & 0.151 & 0 \\
\hline No & $194(87.8)$ & $689(93.5)$ & & $16(100)$ \\
\hline \multicolumn{5}{|l|}{ Litigation, n (\%) } \\
\hline Yes & $13(5.9)$ & $49(6.5)$ & 0.876 & 0 \\
\hline No & $208(94.1)$ & $706(93.5)$ & & $16(100)$ \\
\hline Tobacco use (\%) & 38.5 & 27.8 & $0.003 \dagger$ & \\
\hline Alcohol use (\%) & 26.1 & 30.2 & 0.245 & 12.5 \\
\hline Work status (\%) & 52.2 & 68.2 & $0.001 \dagger$ & \\
\hline
\end{tabular}

ence was not statistically significant, $\mathrm{p}=0.181$ (Table 2). Success, as defined by 15 point NDI improvement, was not different between groups at any time point, and no difference in this outcome measure was present between groups at any follow-up time point (Table 5).

Significant improvement from baseline in arm pain and neck pain was seen in both weak and strong opioid cohorts, and no differences in arm or neck pain scores were present at any follow-up time point (Tables 3 and 4). No significant differences in SF-36 PCS score improvements were present at any follow-up time point (Table 6). Statistically significant differences in SF-36 MCS scores were present, although they did not meet the minimum clinically important difference and are of minimal clinical significance.

Patient-perceived results and patient satisfaction were similar among groups at all follow-up time points (Table 7). Return to work was similar between groups at all follow-up time points. Adverse events reported during the 24-month follow-up period were similar between groups, including events related to reports of neck or arm pain and

TABLE 2. NDI scores across groups*

\begin{tabular}{|c|c|c|c|c|}
\hline $\begin{array}{l}\text { Time } \\
\text { Point }\end{array}$ & Strong Opioid & Weak Opioid & $\begin{array}{c}p \\
\text { Value }\end{array}$ & Naïve \\
\hline Preop & $60.2(15.2,226)$ & $51.9(15.3,761)$ & - & $44.8(14.7,16)$ \\
\hline 6 months & $24.9(21.3,188)$ & $19.8(18.9,704)$ & 0.252 & $20.6(18.6,14)$ \\
\hline 12 months & $23.3(21.8,202)$ & $18.6(19.1,700)$ & 0.454 & $14.3(19.0,15)$ \\
\hline 24 months & $23.9(23.1,191)$ & $18.4(19.4,690)$ & 0.181 & $12.7(16.9,15)$ \\
\hline
\end{tabular}

other pain. There were no differences at any time point in patient satisfaction with the results of the surgery between groups. There were no differences in outcomes when groups were divided by treatment received (ACDF or TDA).

\section{Discussion}

The use of opioids in the initial management of musculoskeletal disease is becoming increasingly common. ${ }^{2}$ In this analysis of 1004 patients with cervical radiculopathy or myelopathy, only $1.6 \%$ of patients were narcotic naïve at the time of enrollment. The American Society of Interventional Pain Physicians has stated that opioid medications may be effective for short-term use in acute pain; however, use that becomes chronic is increasing. ${ }^{13}$ Further, opioids do not appear to be as effective for neuropathic pain as they are for allodynic pain, and, therefore, are generally less effective in the study population. ${ }^{11}$ This chronic use of opioids is concerning as it may lead to tolerance,

TABLE 3. Arm pain assessed using numeric rating scale

\begin{tabular}{lcccc}
\hline $\begin{array}{l}\text { Follow-Up } \\
\text { Time Point }\end{array}$ & $\begin{array}{c}\text { Strong Opioid } \\
\mathrm{n}=226\end{array}$ & $\begin{array}{c}\text { Weak Opioid } \\
\mathrm{n}=762\end{array}$ & $\mathrm{p}$ Value & $\begin{array}{c}\text { Naïve } \\
\mathrm{n}=16\end{array}$ \\
\hline Preop (SD) & $77.7(21.5)$ & $72.0(22.8)$ & $<0.001^{*}$ & $72.2(21.6)$ \\
\hline 6 months & $25.9(-51.8)$ & $22.1(-49.9)$ & $0.328^{* *}$ & $28.3(-43.9)$ \\
\hline 12 months & $23.5(-54.2)$ & $22.6(-49.4)$ & $0.864^{* *}$ & $20.2(-52.0)$ \\
\hline 24 months & $25.4(-52.3)$ & $21.4(-50.6)$ & $0.244^{* *}$ & $18.2(-54.00)$ \\
\hline * From independent-sample t-test. \\
${ }^{* *}$ The p values for comparing treatment groups are from ANCOVA, with the \\
preoperative score as the covariate. \\
$\dagger$ Unless otherwise stated, values are mean score (change from baseline).
\end{tabular}


TABLE 4. Neck pain assessed using numeric rating scale†

\begin{tabular}{lcccc}
\hline $\begin{array}{l}\text { Follow-Up } \\
\text { Time Point }\end{array}$ & $\begin{array}{c}\text { Strong Opioid } \\
\mathrm{n}=226\end{array}$ & $\begin{array}{c}\text { Weak Opioid } \\
\mathrm{n}=762\end{array}$ & $\mathrm{p}$ Value & $\begin{array}{c}\text { Naïve } \\
\mathrm{n}=16\end{array}$ \\
\hline Preop (SD) & $84.6(15.4)$ & $77.6(18.3)$ & $<0.001^{*}$ & $67.7(29.3)$ \\
\hline 6 months & $34.5(-50.1)$ & $29.9(-47.7)$ & $0.431^{* *}$ & $23.9(-43.8)$ \\
\hline 12 months & $31.5(-53.1)$ & $27.6(-50.0)$ & $0.549^{* *}$ & $28.1(-39.6)$ \\
\hline 24 months & $33.9(-52.7)$ & $26.8(-50.8)$ & $0.355^{* *}$ & $23.1(-44.6)$ \\
\hline
\end{tabular}

* From independent-sample t-test.

** The $p$ values for comparing treatment groups are from ANCOVA, with the preoperative score as the covariate.

$\dagger$ Unless otherwise stated, values are mean score (change from baseline).

with escalating doses of opiates, and to opioid-induced hyperalgesia, with paradoxical pain in response to opioid exposure. Both may influence the poor outcomes observed in the nonoperative and operative management of musculoskeletal disease, including cervical degenerative disease. ${ }^{1,3,6,14,15}$ Higher doses of opiates have been correlated with higher complaints of disability, higher rates of treatment noncompliance, and higher rates of surgery. A reasonable fear is that use of stronger opioids may be associated with worse outcomes in anterior cervical decompressive procedures, such as ACDF and TDA.

In this post hoc analysis of data obtained from 2 prospective, randomized, controlled trials of anterior cervical decompressive procedures for single-level radiculopathy or myelopathy we have found no evidence that preoperative narcotic strength affected outcomes. Disease-specific measures (arm pain, neck pain, NDI) and measures of general health (SF-36 PCS) were similar at all follow-up visits for patients with histories of use of either weak or strong opioids. Unfortunately, narcotic-naïve patients were so rare that statistical comparisons were not possible for this group. Nonetheless, the results of the naïve group appear similar to the strong and weak groups. No difference in success rates, as defined by a minimum of 15 point improvement in the NDI, was present at any time point between groups, and patients were similarly pleased with the results of the surgery at all follow-up time points.

It is difficult to contrast the results of this study with prior works investigating the use of opioids and anterior cervical surgery. ${ }^{1,6}$ Lawrence et al. examined the results of 91 consecutive patients treated with ACDF for cervical radiculopathy. ${ }^{6}$ Though the outcome measures reported are not validated, these authors reported good results in only $51 \%$ of patients receiving opioids for 6 months or more before surgery versus good results in $86 \%$ of the opioid-naïve group. The chronic opioid group had $32 \%$ poor results while the opioid-naïve group had no poor results. They conclude that surgeons must counsel patients regarding the risk of poor results after surgery if they have taken opioids for more than 6 months prior to surgery. Their conclusions agree with the findings in total joint arthroplasty, where preoperative opioid intake has been associated with poor results., ${ }^{3,15}$ These studies do not compare the results associated with differing relative strengths of opioids used. The results of our study show that patients receiving high strength opioid pain medications can experience good results and deem their surgeries "successful."
TABLE 5. Success across groups*

\begin{tabular}{lcccc}
\hline Time Point & $\begin{array}{c}\text { Strong } \\
\text { Opioid }\end{array}$ & $\begin{array}{c}\text { Weak } \\
\text { Opioid }\end{array}$ & p Value† & Naïve \\
\hline 6 months & $157(83.5)$ & $562(79.9)$ & 0.778 & $10(71.4)$ \\
\hline 12 months & $169(83.7)$ & $573(82.0)$ & 0.880 & $11(73.3)$ \\
\hline 24 months & $154(80.6)$ & $570(82.7)$ & 0.134 & $11(73.3)$ \\
\hline
\end{tabular}

* Success is defined as a minimum 15-point improvement in NDI score. All values are number $(\%)$ of patients.

$\dagger$ The $p$ values comparing success are from logistic regression adjusted by the preoperative NDI score.

Unfortunately, we are not able to compare opioid-naïve patients with the strong and weak strength groups. An analysis of patients undergoing ACDF in 2 IDE studies found work status, higher disability scores, litigation, and impaired sensory function were associated with poor outcomes. ${ }^{1}$ The strength of the preoperative opioid did not influence results. Our results suggest a similar conclusion.

There are, however, several limitations to this study. We are unable to quantify the dose and duration of preoperative opioid use. Thus, we are unable to calculate a morphine equivalent dose for a more uniform comparison of preoperative intake and any association with results. In some cases, those taking weak opioids may have taken quantities larger than strong opioid patients. At the extreme, the weak opioid cohort may have taken higher morphine equivalent dosing, on average, though the results of the study would be unchanged. Also, we are unable to quantify the duration of symptoms in any patient. Patients with chronic pain and chronic opioid exposure may not have been offered the opportunity to participate in these studies. As a result, there also may be demographic differences between patients deemed candidates for enrollment and those not offered enrollment, which limit the generalizability of our data. The excellent overall results confirm the importance of patient selection for surgery as was presumably done in the rigidly administered trials.

Also a concern with chronic or high dose opioid use is opioid-induced hyperalgesia, where opioid exposure potentiates rather than alleviates pain. While chronic exposure is often associated with this phenomenon, both acute and chronic use can result in this condition. ' A comparison with a narcotic-naïve group is desirable, to evaluate any effect that opioids may have on outcomes, though this was not possible with these data, given the paucity of opioid-naïve patients. That so few patients were opioid naïve points to the ubiquity of the use of opioids in the nonoperative management of cervical degenerative disease with neck and arm pain. The IDE trials excluded patients with histories of drug or alcohol abuse, again limiting the generalizability of the results and highlighting the importance of careful patient selection. Finally, these data come from 2 trials investigating single-level cervical disease. It stands to reason that these findings would transfer to multilevel surgery for radiculopathy or myelopathy, though this may not be the case.

Despite the aforementioned limitations, these data support the idea that opioid strength may not adversely affect outcomes in anterior cervical decompressive procedures. 
TABLE 6. SF-36 scores across groups*

\begin{tabular}{|c|c|c|c|c|}
\hline Follow-Up Time Point \& Variable & Strong Opioid & Weak Opioid & p Value $†$ & Naïve \\
\hline \multicolumn{5}{|l|}{ Preop } \\
\hline PCS & $29.2(6.2,226)$ & $32.9(7.2,761)$ & & $31.0(6.0,13)$ \\
\hline MCS & $40.3(12.0,226)$ & $43.7(12.1,761)$ & & $46.5(14.2,13)$ \\
\hline \multicolumn{5}{|l|}{6 months } \\
\hline PCS & $42.3(11.8,186)$ & $45.4(11.1,700)$ & 0.149 & $16.7(13.8,11)$ \\
\hline MCS & $47.9(12.0,186)$ & $51.2(10.5,700)$ & $0.0008 \ddagger$ & $51.4(11.7,13)$ \\
\hline \multicolumn{5}{|l|}{12 months } \\
\hline PCS & $43.8(11.7,201)$ & $45.8(11.2,697)$ & 0.990 & $49.0(10.3,15)$ \\
\hline MCS & $47.7(12.6,201)$ & $51.6(10.3,697)$ & $<0.001 \ddagger$ & $53.0(9.0,15)$ \\
\hline \multicolumn{5}{|l|}{24 months } \\
\hline PCS & $43.5(12.4,189)$ & $46.3(11.4,683)$ & 0.317 & $51.2(8.2,14)$ \\
\hline MCS & $47.8(12.3,189)$ & $51.5(10.4,683)$ & $0.003 \ddagger$ & $51.8(11.9,14)$ \\
\hline
\end{tabular}

* All values are mean score (SD, number of patients).

$\dagger p$ values are from ANCOVA, with preoperative score as a covariate.

$\ddagger$ Represents statistical significance.

It is unlikely that any prospective cohort will be able to enroll a similar number of patients, which is a strength of the data presented here. The weaknesses of this study should be used to help guide the design of a prospective, obser- vational cohort study. To confirm, or refute, these conclusions, a study will need to collect duration of symptoms, duration of opioid use, average daily morphine equivalent opioid consumption, and postoperative opioid use. Such a

TABLE 7. Patient perception and satisfaction results*

\begin{tabular}{|c|c|c|c|c|c|}
\hline Assessment Item & $\begin{array}{l}\text { Pt Perception at } \\
\text { Follow-Up }\end{array}$ & $\begin{array}{l}\text { Strong Opioid } \\
n=226\end{array}$ & $\begin{array}{c}\text { Weak Opioid } \\
n=762\end{array}$ & p Value & $\begin{array}{l}\text { Naïve } \\
n=16\end{array}$ \\
\hline \multirow[t]{9}{*}{ I am satisfied with the results of my surgery } & 6 months & & & & \\
\hline & Yes & $164(87.2)$ & $608(86.7)$ & 0.904 & $13(92.9)$ \\
\hline & No & $24(12.8)$ & $93(13.3)$ & & $1(7.1)$ \\
\hline & 12 months & & & & \\
\hline & Yes & $176(87.1)$ & $577(82.7)$ & 0.713 & $15(100)$ \\
\hline & No & $26(12.9)$ & $121(17.3)$ & & 0 \\
\hline & 24 months & & & & \\
\hline & Yes & $167(87.4)$ & $603(86.6)$ & 0.130 & $14(93.3)$ \\
\hline & No & $24(12.6)$ & $93(13.4)$ & & $1(7.1)$ \\
\hline \multirow[t]{9}{*}{ I was helped as much as I thought I would be } & 6 months & & & & \\
\hline & Yes & $156(83.4)$ & $577(82.7)$ & 0.913 & $13(92.9)$ \\
\hline & No & $31(16.6)$ & $121(17.3)$ & & $1(7.1)$ \\
\hline & 12 months & & & & \\
\hline & Yes & 168 (83.2) & $574(82.4)$ & 0.834 & $15(100)$ \\
\hline & No & $34(16.8)$ & $123(17.6)$ & & 0 \\
\hline & 24 months & & & & \\
\hline & Yes & $160(84.7)$ & $587(87.3)$ & 0.729 & $13(86.7)$ \\
\hline & No & $29(15.3)$ & $99(14.4)$ & & $2(13.3)$ \\
\hline \multirow[t]{9}{*}{ I would have the surgery for this condition again } & 6 months & & & & \\
\hline & Yes & $167(89.3)$ & $603(86.6)$ & 0.389 & $14(93.3)$ \\
\hline & No & $20(10.7)$ & $93(13.4)$ & & $1(6.7)$ \\
\hline & 12 months & & & & \\
\hline & Yes & $177(88.1)$ & $610(87.9)$ & 1.000 & $13(86.7)$ \\
\hline & No & $24(11.9)$ & $84(12.1)$ & & $2(13.3)$ \\
\hline & 24 months & & & & \\
\hline & Yes & $171(90.5)$ & $596(87.3)$ & 0.257 & $13(86.7)$ \\
\hline & No & $18(9.5)$ & 87 (12.7) & & 2 (13.3) \\
\hline
\end{tabular}

$\mathrm{Pt}=$ patient.

* All values are number (\%) of patients.

$\dagger$ The $p$ values are from Fisher's exact test. 
study is necessary given the common use of opioids in the nonoperative management of these pathologies.

\section{Conclusions}

In this post hoc analysis of data obtained from 2 prospective IDE trials, we found no association between preoperative narcotic intake and poor outcomes following anterior decompressive surgery for single-level cervical disease. The prevalence of narcotic use in the nonoperative management of these pathologies is high, with few narcotic-naïve patients enrolled in either study. Despite the prevalence of opioid use, no difference was observed between patients taking high or low strength opioids, and good results were obtained in the majority of cases. These data will aid surgeons in counseling patients prior to anterior cervical decompressive surgeries for single-level disease and confirm the importance of careful patient selection when performing these procedures. These results should allay fears of surgeons that high strength narcotic use precludes good results following the treatment of single-level cervical degenerative disease.

\section{References}

1. Anderson PA, Subach BR, Riew KD: Predictors of outcome after anterior cervical discectomy and fusion: a multivariate analysis. Spine (Phila Pa 1976) 34:161-166, 2009

2. Caudill-Slosberg MA, Schwartz LM, Woloshin S: Office visits and analgesic prescriptions for musculoskeletal pain in US: 1980 vs. 2000. Pain 109:514-519, 2004

3. Franklin PD, Karbassi JA, Li W, Yang W, Ayers DC: Reduction in narcotic use after primary total knee arthroplasty and association with patient pain relief and satisfaction. J Arthroplasty 25 (6 Suppl):12-16, 2010

4. Heller JG, Sasso RC, Papadopoulos SM, Anderson PA, Fessler RG, Hacker RJ, et al: Comparison of BRYAN cervical disc arthroplasty with anterior cervical decompression and fusion: clinical and radiographic results of a randomized, controlled, clinical trial. Spine (Phila Pa 1976) 34:101-107, 2009

5. Kidner CL, Mayer TG, Gatchel RJ: Higher opioid doses predict poorer functional outcome in patients with chronic disabling occupational musculoskeletal disorders. J Bone Joint Surg Am 91:919-927, 2009

6. Lawrence JT, London N, Bohlman HH, Chin KR: Preoperative narcotic use as a predictor of clinical outcome: results following anterior cervical arthrodesis. Spine (Phila Pa 1976) 33:2074-2078, 2008

7. Lee M, Silverman SM, Hansen H, Patel VB, Manchikanti L: A comprehensive review of opioid-induced hyperalgesia. Pain Physician 14:145-161, 2011

8. Mummaneni PV, Burkus JK, Haid RW, Traynelis VC, Zde- blick TA: Clinical and radiographic analysis of cervical disc arthroplasty compared with allograft fusion: a randomized controlled clinical trial. J Neurosurg Spine 6:198-209, 2007

9. Murrey D, Janssen M, Delamarter R, Goldstein J, Zigler J, Tay B, et al: Results of the prospective, randomized, controlled multicenter Food and Drug Administration investigational device exemption study of the ProDisc-C total disc replacement versus anterior discectomy and fusion for the treatment of 1-level symptomatic cervical disc disease. Spine J 9:275-286, 2009

10. Peolsson A, Vavruch L, Oberg B: Predictive factors for arm pain, neck pain, neck specific disability and health after anterior cervical decompression and fusion. Acta Neurochir (Wien) 148:167-173, 2006

11. Phillips WJ, Currier BL: Analgesic pharmacology: I. Neurophysiology. J Am Acad Orthop Surg 12:213-220, 2004

12. Riew KD, Buchowski JM, Sasso R, Zdeblick T, Metcalf NH, Anderson PA: Cervical disc arthroplasty compared with arthrodesis for the treatment of myelopathy. J Bone Joint Surg Am 90:2354-2364, 2008

13. Trescot AM, Helm S, Hansen H, Benyamin R, Glaser SE, Adlaka R, et al: Opioids in the management of chronic noncancer pain: an update of American Society of the Interventional Pain Physicians' (ASIPP) Guidelines. Pain Physician 11 (2 Suppl):S5-S62, 2008

14. Webster BS, Verma SK, Gatchel RJ: Relationship between early opioid prescribing for acute occupational low back pain and disability duration, medical costs, subsequent surgery and late opioid use. Spine (Phila Pa 1976) 32:2127-2132, 2007

15. Zywiel MG, Stroh DA, Lee SY, Bonutti PM, Mont MA: Chronic opioid use prior to total knee arthroplasty. J Bone Joint Surg Am 93:1988-1993, 2011

\section{Author Contributions}

Conception and design: Kelly, Riew. Acquisition of data: Anderson, Sasso, Riew. Analysis and interpretation of data: Kelly, Anderson. Drafting the article: Kelly. Critically revising the article: all authors. Reviewed submitted version of manuscript: all authors. Approved the final version of the manuscript on behalf of all authors: Kelly.

\section{Supplemental Information}

\section{Previous Presentation}

Portions of this work were presented in 2012 in abstract form at the 40th Annual Meeting of the Cervical Spine Research Society (December 6-8, Chicago, Illinois).

\section{Correspondence}

Michael P. Kelly, Department of Orthopedic Surgery, Institutes of Health, 5th Fl., Washington University School of Medicine, 660 S. Euclid Ave., Saint Louis, MO 63110. email: kellymi@ wudosis.wustl.edu. 